\title{
Evolutionary Game Model of Integrating Health and Care Services for Elder People
}

\author{
Tingqiang Chen $\mathbb{D}$, Jinnan Pan, Yuanping He $\mathbb{B}$, and Jining Wang $(\mathbb{B}$ \\ School of Economic and Management, Nanjing Tech University, Nanjing 211816, China \\ Correspondence should be addressed to Yuanping He; heyp0913@njtech.edu.cn
}

Received 8 May 2020; Accepted 29 May 2020; Published 7 July 2020

Guest Editor: Baogui Xin

Copyright (c) 2020 Tingqiang Chen et al. This is an open access article distributed under the Creative Commons Attribution License, which permits unrestricted use, distribution, and reproduction in any medium, provided the original work is properly cited.

\begin{abstract}
With the background of aging, ensuring the deep integration of pension and medical services and effectively integrating pension resources and medical resources are hot issues that must be addressed in the current mode of integrating health and care services for older people. Thus, we use game theory to construct the utility model of resource allocation between pension and medical institutions. We apply this model to explore how pension institutions and medical institutions invest resources into the integration of health and care services, analysis of influencing factors, and conducting incentive mechanism research by using MATLAB 2016b software. Through theoretical deduction and experimental analysis, the following conclusions are drawn. First, the income distribution coefficient of pension institutions is positively correlated with the level of labor input, and its growth rate has a marginal diminishing effect on the level of labor. Second, in early investment, the income distribution coefficient of pension institutions is positively correlated with fixed asset investment regardless of the different effort coefficients between medical institutions and pension institutions. With a high income distribution coefficient, pension institutions are negatively correlated and marginally decrease. Third, in early investment, the income distribution coefficient of pension institutions is positively correlated with medical institutions' labor input level. When the income distribution coefficient of pension institutions reaches a certain value, it is negatively correlated with the labor input level of medical institutions, thereby showing a marginal diminishing effect.
\end{abstract}

\section{Introduction}

China has become an aging society since 2000, and its population is rapidly aging and becoming disabled. According to the Statistical Communique on National Economic and Social Development in 2017, the number of people aged 60 and over has reached 241 million, accounting for $17.3 \%$ of the total population. Among them, the number of people aged 65 and above reached 158 million, accounting for $11.4 \%$ of the total population. China's aging population is expected to reach 487 million in 2050, accounting for about one-third of the total population. The number of elderly people and the proportion of the total population will reach a peak. With the background of aging, the number of disabled elderly is bound to increase, and their dual demands for life care and medical rehabilitation are increasingly becoming prominent. At present, China's old-age care work is facing the problem of serious separation of medical care and old-age resources, and the pension service system cannot meet the medical service needs of the elderly. Most pension institutions are only responsible for the daily life care and cannot meet the elderly's need for medical and health services. On the contrary, medical institutions mainly aim to provide medical and health services for residents, which prevent them from also giving elderly care services. Therefore, health and care service integration was born. How to ensure the deep integration of elderly care services and medical services and how to effectively integrate elderly care resources with medical resources are hot issues that need to be solved urgently in the current situation of integrated elderly care services. 
Theoretical exploration about health and care service integration started late in China, and it needs further understanding. The integrating of health and care services for elder people is a new concept with Chinese characteristics for a new era. It refers to the integration of medical resources and old-age care resources, which can not only meet the basic care needs of the elderly but also meet certain medical needs of the elderly, so as to maximize the utilization of social resources. Health services include medical rehabilitation services, health consultation and examination services, disease diagnosis and care services, serious illness rehabilitation services, and hospice care services. Old-age care service refers to housing, life care, rehabilitation nursing, spiritual comfort, and cultural entertainment services. The health and care service integration is a new type of health and old-age care service mode, which is based on the basic old-age care service. This mode provides good life care, spiritual comfort, and other services for the elderly, and it focuses on improving the quality of medical services such as disease diagnosis, treatment and nursing, health examination, serious illness rehabilitation, and hospice care [1]. To achieve this purpose, the government actively promotes the combination of medical and old-age care services and advocates multiple integrations of medical and old-age care resources to solve the current problem about the separation of health and care. At present, the main problems in the elderly care work are that the number of beds and professional staff are far less than the demand. In addition, the elderly care service projects and facilities are relatively simple and cannot meet the diversified medical and care needs of the elderly. Therefore, realizing the integration of medical care and old-age care services and fully utilizing separated medical and old-age care resources are the focus of old-age care work.

Upon reviewing extensive literature, the findings show that traditional family care resources are gradually reduced with the acceleration of aging, thereby resulting in the increasing contradiction between supply and demand of longterm care services. In recent years, the population of elderly with disabilities, chronic diseases, and terminal diseases has increased rapidly. China's population is aging seriously, and the social pension security burden is heavy $[2,3]$. From the perspective of big health, the goal of integrating health and care services is to develop and maintain the healthy life of the elderly and realize healthy aging $[4,5]$. Hence, long-term care services have become an important part of medical and care services. Jacobzone and Jenson [6] mentioned that longterm care services rely on a partnership among formal care institutions, the state, and families. Ikegami and Campbell [7] believed that an effective long-term care system should be public, comprehensive, independent, primarily communitybased, and separate from medical and social services. The model of integrated health and care services for the aged was an important measure to solve the global pension problem and improve the level of social services in the new era. Hartgerink et al. [8] compared the situational awareness, nursing coordination, and integrated care in different hospitals in the Netherlands and proved that integrated care could improve the care quality and health status of elderly patients. Fabbricotti et al. [9] used a quasi-experimental method to evaluate the effect of combined medical and nursing services on the improvement of the quality of life and medical effects of frail elderly people. Bao et al. [10] used 13 nursing homes in Wuhan, China, as an example to explore the influence of medical-nursing combined care on the health status and service satisfaction of the elderly. Reuben [11] said that providing health care to older patients alone is unlikely to produce good results. Wendy et al. [12] argued that focusing on the daily care of elderly patients is more important than curing the disease itself.

The first countries to realize the presence of an aging population were the Western industrialized nations. Therefore, foreign scholars began to study pension problems early on, and the Western pension model gradually emerged. Powell [13] believed that social pension services should be personalized to meet the living needs of different elderly people. This kind of personalized pension service will increase the participation of elderly people and promote pension service that fits the actual situation to eliminate the cost of social pension service. After controlling for age, gender, years of education, and other factors, Zunzunegui et al. [14] found that emotional and material support from children were significantly correlated with self-rated health. People who live with their children after the death of a spouse are in better health than those who live alone after. Hughes and Waite [15] argued that a clear correlation exists between pension patterns and self-reported health, mortality, and depression. Lund et al. [16] found that older adults who lived with other people had significantly lower death rates than those who lived alone. Therefore, the health and longevity of the elderly can only improve by combining the government, children, and the elderly.

Since the 1980s, many countries began to carry out theoretical research and practice of integrated care for the elderly. Britain first put forward the concept of "integrated care." Glendinning [17] combined two integrated care promotion plans about the integration of family doctors with community medical institutions and integration of social services and medical institutions; he concluded that structural integration helps transform the decentralized system into a service planning and supply system with synergistic amplification effect. Michel [18] believed that integrated care aimed to provide multidimensional, comprehensive, and detailed care services for the elderly with similar problems or needs. Many scholars have also carried out numerous analyses on policy implementation and its effects. Leichsenring and Alaszewski [19] summed up the general situation of the nine EU member states' integration care and pointed out that horizontal integration is the most extensive practical idea. Reed et al. [20] divided the integrated care into system, institution, and individual levels. The system level was the overall integration of different regions and management departments. The institutional level was the division of labor and cooperation within or between pension service institutions. The individual level involves enhancing the comprehensiveness of the individual's care. Fisher and Elnitsky [21] pointed out that integrated care aimed to take the elderly as the center and family 
and community as the carrier and integrate health, service, and social care resources to provide care, assessment, and supervision for the elderly in life, physiology, and psychology. The development of elderly care services in the United States could be divided into three stages, namely, preparatory, development, and mature stages. Sultz [22] introduced the basic situation of these three stages. The preparatory phase was the establishment of Medicare and Medicaid in 1965. The development period was 1965 to 1990, whereas the maturity period was from 1990 to present. In the research on the model of medical and nursing care, Carson et al. [23] pointed out that LTAC was the typical representative of the new nursing mode that combines medical treatment and nursing in America. Long-term acute-care hospitals, which provide care to patients suffering from prolonged critical illness, are exempted from the Medicare prospective payment system. The PACE (Program of All Inclusive Care for the Elderly) proposed by the United States aims to provide the elderly with a full range of services, including daily life care, medical rehabilitation, spiritual comfort, and emergency rescue. Chatterji et al. [24] found that PACE can effectively reduce the frequency and time of hospitalization in the long run, and it can help improve the elderly's physical and mental state and quality of life in the short run. Laura and Gadsby [25] also thought that individuals must be at least 55 years old, state-eligible for nursing home care, and living in the program's geographical catchment area. Segelman et al. [26] pointed out that PACE provides continuous services, including primary care, diagnosis, treatment, nursing, and daily care. Integrating the financial resources for Medicare and Medicaid, the entrusted unit must achieve a certain quality of service under a fixed amount of per-person billing and bear its own financial losses. Fretwell et al. [27] found that 104 PACE service centers had opened in 31 states by the end of 2013. Polska [28] pointed out that PACE is directly managed by the government, based on community, guaranteed by public finance and commercial resources, and characterized by integration of medical and nursing care. It aims to provide continuous elderly care services to the frail and high-risk elderly. In Germany, the mode of integrated care for the elderly is provided by social institutions. According to Geraedts et al. [29], older people receive financial compensation by buying long-term care insurance. The new models of choice of care have recently been introduced in Sweden's health care. Ahgren [30] stated that citizens act as purchasers; they can choose the primary care center or family physician they want to be treated by, which in turn generates a capitation payment to the chosen unit.

According to the abovementioned research, it can be found that the theoretical research on the mode of integrating health and care services is mostly limited to economics, management, sociology, and demography. Scholars tend to make more qualitative analysis, while there are few researches on quantitative analysis. The new pension mode combines medical and pension resources. In the process of mutual cooperation between pension and medical institutions, their own benefits and costs will be involved. Both are driven by their own interests and form the game theory of intersecting interests among subjects. Maruthappu et al. [31] proposed that integrated care projects can achieve the intensification of health resources and the maximization of service efficiency, but the allocation, management, and use of funds as well as service personnel need to be further improved. Shimizutani [32] also studied the cost-effectiveness and incentive mechanism of combining medical care with old-age care. Game theory is an important subject of operational research and can study the multisubject interest in the mode of integrating health and care services for elder people. In existing studies, scholars used game theory to explore the competition and cooperation between economic entities. Ji et al. [33] proposed that suppliers and manufacturers are multistakeholders. They should establish a long-term green purchasing relationship. In addition, they established the evolutionary game model to observe the trend of multistakeholder cooperation to guide stakeholders in making better choices in the future. Li et al. [34] established the cooperative game model of benefit distribution in the supply chain to enhance the stability of partners in the VMI model. The high inventory cost of VMI members will lead to increasing the surplus value of other members under fair distribution. Alavi and Zhou [35] mentioned that cooperative game theory can be applied to positive frequency division multiple access network to realize fair allocation of resources.

Resource integration is also very important in integrating care. Through literature review, we found that resource integration researchers often start from the perspective of social resource integration. They then integrate and innovate information, technology, products, and other resources while creating value together and realizing the maximization of social benefits. Zhang et al. [36] studied the service system of bilateral resource integration by combining the service of providers with the personalized needs of customers; this work aimed to transform the servitization of real resources into service resources by studying service resources. Wan and Zhang [37] explored how the resource integrators cocreate value closely under the rubric of S-D logic and systems and further proposed a conceptual model for deeply understanding the roles of focal actors and others in a service ecosystem. Siltaloppi and Vargo [38] provided that reconciling resource integration and value propositions is the dynamics of value cocreation and propositions as the cocreated forms of shared resources and understanding, which constitutes service systems. Singaraju et al. [39] mentioned that actor interaction is the basis of value cocreation through resource integration. Information transforms social media platform's technological functions into resources, and the social media platform is a "systems resource integrator." Guan et al. [40] studied the resource integration of virtual industry cluster; he used the complex network model to analyze the virtual industrial cluster and promote its resource integration and development. To realize value cocreation, Koskela-Huotari et al. [41] proposed to innovate and reform the rules of resource integration in the service ecosystem based on service-dominant logic and institutional theory. Based on the study of China's express market, Wang et al. [42] found that the express industry was 
fragmented, and the service quality was poor. He then proposed the service network cooperation model of horizontal resource integration to maximize the benefits of the network cooperation model.

Literature review also showed that existing scholars have explored the mode of integrating health and care services and its operation mechanism. However, only a few of them have applied quantitative methods to study the resource allocation problem under this mode. Therefore, we use game theory to construct the utility model of resource allocation between pension and medical institutions and explore how pension institutions and medical institutions invest resources in the integration of health and care services. We also analyze the influencing factors and conduct incentive mechanism research and solve the dilemma in the current pension problem. This is also the innovation and motivation of this article.

The remainder of this work is organized as follows. Section 2 builds the utility model of resource allocation between pension and medical institutions. Section 3 analyzes the influencing factors and conducts incentive mechanism research on pension institutions and medical institutions via simulation. Section 4 summarizes and concludes the research.

\section{Constructing the Utility Model of Resource Allocation between Pension and Medical Institutions}

2.1. Model Assumption. The resource input in integrating health and care services for older people mainly involves intangible human resources, tangible monetary capital, and fixed assets. Effective integration of these resources can result in high level of pension services. We make the following assumptions so that the model is more realistic:

Assumption 1. Pension institutions and medical institutions cooperate to provide integrating health and care services. Pension institutions are the dominant provider of integrating health and care services, whereas medical institutions are the suppliers.

Assumption 2. In the process of providing integrating health and care services for older people, a certain number of elderly users will continue to purchase this new type of pension services.

Assumption 3. In the process of providing integrating health and care services for older people, pension institutions invest in staff and infrastructure equipment, while medical institutions only invest in staff.

Assumption 4. There is a quadratic function relationship between the service effort cost and the level of staff input between the pension institution and medical institution.

Assumption 5. Both pension institutions and medical institutions aim to maximize their own income.

The notations for variables and parameters are given in Table 1.
2.2. Model Construction. Cobb-Douglas production function is used to build the input and output model, which is about the cooperation between pension institutions and medical institutions to build a new type of pension service combining health and care for older people:

$$
Y=A\left(L_{1}+L_{2}\right)^{\alpha} K^{\beta},
$$

where $L_{1}$ mainly reflects the professional ability and working time input of nursing staff in pension institutions; $L_{2}$ mainly reflects the professional ability and working time of the medical staff involved in the integrating health and care services; $K$ mainly reflects their capital investment in nursing beds, basic medical facilities, and equipment; and $\alpha+\beta=1$.

In income distribution, pension institutions and medical institutions aim to maximize their own income, and the absolute income functions of pension institutions and medical institutions are as follows:

$$
\begin{aligned}
& P_{1}=\lambda_{1} Y-\frac{1}{2} a_{1} L_{1}^{2}-K, \\
& P_{2}=\lambda_{2} Y-\frac{1}{2} a_{2} L_{2}^{2},
\end{aligned}
$$

where $\lambda_{1}+\lambda_{2}=1$. The effort cost of nursing staff invested in pension institutions is $(1 / 2) a_{1} L_{1}^{2}$, whereas the effort cost of medical institutions' staff participating in integrating health and care services is $(1 / 2) a_{1} L_{2}^{2}$. The medical staff invested in medical institutions have professional medical aid skills, and the nursing staff invested in pension institutions need to undergo certain medical organization training. Thus, the medical staff in medical institutions can provide nearly the same service value as the nursing staff in pension institutions with less effort. Hence, assume that $a_{1}>a_{2}$.

To explore the relationship among absolute benefits, labor force, and fixed asset investment of pension and medical institutions, two types of economic actors are considered. The first partial derivative of formula (2) on the labor level of pension institutions can be obtained as follows:

$$
\frac{\partial P_{1}}{\partial L_{1}}=\lambda_{1} A \alpha\left(\lambda_{1}+\lambda_{2}\right)^{\alpha-1} K^{\beta}-a_{1} L_{1} .
$$

The first partial derivative of formula (2) on the fixed asset investment of pension institutions can be obtained as follows:

$$
\frac{\partial P_{1}}{\partial K}=\lambda_{1} A\left(\lambda_{1}+\lambda_{2}\right)^{\alpha} \beta K^{\beta-1}-1
$$

The first partial derivative of formula (3) on the labor level of medical institutions can be obtained as follows:

$$
\frac{\partial P_{2}}{\partial L_{2}}=\lambda_{2} A \alpha\left(\lambda_{1}+\lambda_{2}\right)^{\alpha-1} K^{\beta}-a_{2} L_{2} .
$$

2.3. Model Analysis. To find the optimal value of resource input when the absolute benefits of the two types of economic actors about the pension and medical institutions 
TABLE 1: Variables and notations.

\begin{tabular}{lc}
\hline Notations & Meaning \\
\hline$Y$ & The total revenue from integrating health and care services \\
$P_{1}$ & The absolute income functions of pension institutions \\
$P_{2}$ & The absolute income functions of medical institutions \\
$L_{1}$ & The labor input level of pension institutions in the cooperation between pension and medical institutions \\
$L_{2}$ & The labor input level of medical institutions in the cooperation between pension and medical institutions \\
$K$ & The asset input level of pension institutions \\
$\alpha$ & The output elasticity of labor input \\
$\beta$ & The output elasticity of fixed asset input \\
$A$ & The profitability or marginal output efficiency of the integrating health and care services \\
$\lambda_{1}$ & The income distribution coefficient of pension institutions \\
$\lambda_{2}$ & The income distribution coefficient of medical institutions \\
$a_{1}$ & The effort coefficients of pension institutions \\
$a_{2}$ & The effort coefficients of medical institutions \\
\hline
\end{tabular}

reach the maximum value, set formulas (4)-(6), which can be solved as follows:

$$
\begin{aligned}
L_{1}^{*} & =\lambda_{1}^{1 / \alpha} A^{1 / \alpha} \frac{1}{a_{1}} \frac{\alpha}{\beta} \beta^{1 / \alpha}, \\
K^{*} & =\left(1+\frac{\lambda_{2} a_{1}}{\lambda_{1} a_{2}}\right) \lambda_{1}^{2 / \alpha} A^{2 / \alpha} \frac{1}{a_{1}} \frac{\alpha}{\beta} \beta^{2 / \alpha}, \\
L_{2}^{*} & =\lambda_{2} \lambda_{1}^{\beta / \alpha} A^{\beta / \alpha} \frac{1}{a_{2}} \frac{\alpha}{\beta} \beta^{\beta / \alpha} .
\end{aligned}
$$

Formulas (7)-(9) show that a certain correlation exists between the income distribution coefficient of pension and medical institutions and their investment. To a certain extent, the income distribution coefficient has a positive incentive and constraint effect on the resource investment of the two types of economic actors. Under the mode of integrating health and care services for older people, pension institutions are the leading providers and operators of the pension services, whereas medical institutions are the providers of medical services. Therefore, this work mainly explores the incentive relationship between income distribution coefficient of pension institutions, labor level of pension institutions, fixed asset investment level of pension institutions, and labor level of medical institutions.

\subsubsection{The Effect of Income Distribution Coefficient on the} Level of Labor in Pension Institutions. According to formula (7), the first partial derivative of $\lambda_{1}$ with respect to $L_{1}$ can be obtained as follows:

$$
\frac{\partial \lambda_{1}}{\partial L_{1}}=\frac{a_{1}^{\alpha}}{A}\left(\frac{\alpha}{\beta}\right)^{\beta} L_{1}^{\alpha-1}>0 .
$$

Formula (10) reflects the impact of pension institutions' labor input level on the income distribution coefficient of pension service institutions. $\left(\partial \lambda_{1} / \partial L_{1}\right)>0$ shows that the income distribution coefficient of pension institutions will increase along with the labor input level. According to formula (10), the second partial derivative of $\lambda_{1}$ with respect to $L_{1}$ can be obtained as follows:

$$
\frac{\partial^{2} \lambda_{1}}{\partial L_{1}^{2}}=\frac{a_{1}^{\alpha}}{A}\left(\frac{\alpha}{\beta}\right)^{\beta}(\alpha-1) L_{1}^{\alpha-2}<0 .
$$

Formula (11) reflects the influence of labor input level on the growth rate of pension institutions' income distribution coefficient. $\left(\partial^{2} \lambda_{1} / \partial L_{1}^{2}\right)<0$ shows that the income distribution coefficient of pension institutions decreases marginally with the change of labor level.

Theorem 1. When the benefits of pension institutions are maximized, the income distribution coefficient of pension institutions increases with the improvement of labor input level, and the growth rate decreases marginally with the improvement of labor input level.

Therefore, pension institutions can recruit more professionals, carry out vocational training for nursing staff, cooperate with medical institutions to learn, improve the treatment of nursing staff, and stimulate work enthusiasm to improve the quantity and quality of labor level. Medical institutions reduce the income distribution coefficient when the pension institutions' income distribution coefficient increases because the sum of income distribution coefficient of pension and medical institutions is 1 . Hence, to prevent medical institutions from having a low income distribution coefficient and refusing medical cooperation, pension institutions' labor input needs relaxation and not blindly.

\subsubsection{The Effect of Income Distribution Coefficient on the} Level of Fixed Assets Investment in Pension Institutions. According to formula (8), the first partial derivative of $\lambda_{1}$ with respect to $K$ can be obtained as follows:

$$
\frac{\partial \lambda_{1}}{\partial K}=A^{-(2 / \alpha)} a_{2} \beta^{1-(2 / \alpha)} \lambda_{1}^{-(2 \beta / \alpha)}\left[2\left(\frac{a_{2}}{a_{1}}-1\right) \lambda_{1}+1+\beta\right]^{-1} .
$$

Formula (12) reflects the influence of pension institutions' fixed assets investment on the income distribution coefficient of pension institutions. According to formula (12), the second partial derivative of $\lambda_{1}$ with respect to $K$ can be obtained as follows: 


$$
\frac{\partial^{2} \lambda_{1}}{\partial K^{2}}=-2 A^{-(4 / \alpha)} a_{2}^{2} \beta^{2-(2 / \alpha)} \frac{1+\beta}{\alpha} \lambda_{1}^{-(4 \beta / \alpha)-1}\left[2\left(\frac{a_{2}}{a_{1}}-1\right) \lambda_{1}+1+\beta\right]^{-3}\left[\left(\frac{a_{2}}{a_{1}}-1\right) \lambda_{1}+\beta\right]
$$

Formula (13) reflects the influence of fixed asset investment level on the growth rate of the income distribution coefficient of pension institutions. According to formulas (12) and (13), the incentive relationship between the income distribution coefficient of pension institutions and the level of fixed assets investment of pension institutions is related to the value of the effort coefficient about pension and medical institutions.

To study the influence of fixed asset investment level on the income distribution coefficient of pension institutions, according to formula (12), let $2\left(\left(a_{2} / a_{1}\right)-1\right) \lambda_{1}+1+\beta=0$, and we obtain $\lambda_{1}^{\prime}=(1+\beta) a_{1} / 2\left(a_{1}-a_{2}\right)$.

According to formula (13), let $\left(\left(a_{2} / a_{1}\right)-1\right) \lambda_{1}+\beta=0$, and we obtain $\lambda_{1}^{\prime \prime}=\beta a_{1} / a_{1}-a_{2}$.

The results show that $\lambda_{1}^{\prime \prime}<\lambda_{1}^{\prime}$. Because $0 \leq \lambda_{1} \leq 1$ and the size of $\lambda_{1}^{\prime}$ and $\lambda_{1}^{\prime \prime}$ cannot be determined, compare $\lambda_{1}^{\prime}, \lambda_{1}^{\prime \prime}$ and 1 , then discuss them separately. The following three cases emerge:

Case 1. When $\lambda_{1}^{\prime \prime}<\lambda_{1}^{\prime}<1$, that means $(1+\beta) a_{1} /$ $2\left(a_{1}-a_{2}\right)<1$. Hence, we obtain $0<a_{2}<(\alpha / 2) a_{1}$.

(1) When $0<\lambda_{1}<\lambda_{1}^{\prime \prime}, \quad\left(\partial \lambda_{1} / \partial K\right)>0$ can be obtained from formula (12). Thus, the income distribution coefficient of pension institutions will increase with increasing pension institutions' fixed assets investment. According to formula (13), $\left(\partial^{2} \lambda_{1} / \partial K^{2}\right)<0$ can be obtained. Hence, the income distribution coefficient of pension institutions decreases marginally with increasing fixed asset investment.

(2) When $\lambda_{1}^{\prime \prime}<\lambda_{1}<\lambda_{1}^{\prime}, \quad\left(\partial \lambda_{1} / \partial K\right)>0$ can be obtained from formula (12). Hence, the income distribution coefficient of pension institutions will increase with increasing pension institutions' fixed assets investment. According to formula (13), $\left(\partial^{2} \lambda_{1} / \partial K^{2}\right)<0$ can be obtained. Thus, the income distribution coefficient of pension institutions increases marginally with increasing fixed asset investment.

(3) When $\lambda_{1}^{\prime}<\lambda_{1}<1, \quad\left(\partial \lambda_{1} / \partial K\right)<0$ can be obtained from formula (12). Therefore, the income distribution coefficient of pension institutions will decrease with increasing pension institutions' fixed assets investment. According to formula (13), $\left(\partial^{2} \lambda_{1} / \partial K^{2}\right)<0$ can be obtained. Hence, the income distribution coefficient of pension institutions decreases marginally with increasing fixed asset investment.

Case 2. When $\lambda_{1}^{\prime \prime}<1<\lambda_{1}^{\prime}$, that means
$\left\{\begin{array}{l}\left(\beta a_{1} / a_{1}-a_{2}\right)<1 \\ (1+\beta) a_{1} / 2\left(a_{1}-a_{2}\right)>1\end{array}\right.$. Hence, we obtain
$(\alpha / 2) a_{1}<a_{2}<\alpha a_{1}$.
(1) When $0<\lambda_{1}<\lambda_{1}^{\prime \prime},\left(\partial \lambda_{1} / \partial K\right)>0$ can be obtained from formula (12). Therefore, the income distribution coefficient of pension institutions will increase with increasing pension institutions' fixed assets investment. According to formula (13), $\left(\partial^{2} \lambda_{1} / \partial K^{2}\right)<0$ can be obtained. Thus, the income distribution coefficient of pension institutions decreases marginally with increasing fixed asset investment.

(2) When $\lambda_{1}^{\prime \prime}<\lambda_{1}<1, \quad\left(\partial \lambda_{1} / \partial K\right)>0$ can be obtained from formula (12). Therefore, the income distribution coefficient of pension institutions will increase with increasing pension institutions' fixed assets investment. According to formula (13), $\left(\partial^{2} \lambda_{1} / \partial K^{2}\right)<0$ can be obtained. Thus, the income distribution coefficient of pension institutions increases marginally with increasing fixed asset investment.

Case 3. When $1<\lambda_{1}^{\prime \prime}<\lambda_{1}^{\prime}$, that means $\left(\beta a_{1} / a_{1}-a_{2}\right)>1$. Hence, we can obtain $\alpha a_{1}<a_{2}<a_{1}$.

(1) $\left(\partial \lambda_{1} / \partial K\right)>0$ can be obtained from formula (12). Therefore, the income distribution coefficient of pension institutions will increase with increasing pension institutions' fixed assets investment. According to formula (13), $\left(\partial^{2} \lambda_{1} / \partial K^{2}\right)<0$ can be obtained. Thus, the income distribution coefficient of pension institutions decreases marginally with increasing fixed asset investment.

Theorem 2. The effort coefficient of pension institutions and medical institutions is significantly different for pension institutions in the early stage of the cooperation. Thus, as pension institutions increased fixed assets investment, pension institutions will have bigger income distribution coefficient, which reaches a certain value. Pension institutions' income distribution coefficient will decrease with increasing fixed asset investment. When the difference of the effort coefficient between pension and medical institutions decreases gradually, the income distribution coefficient of pension institutions increases with increasing fixed asset investment.

Therefore, pension institutions can increase their income distribution coefficient by expanding the fixed assets investment regardless of the difference between the effort coefficient of medical and pension institutions. When the effort coefficient of medical institutions is relatively low, then medical institutions are not highly motivated to participate in integrating health and care services. Therefore, if pension institutions want to continue to obtain increased income distribution after their income distribution coefficient reaches a certain value, then they need to appropriately reduce the fixed assets investment. 
2.3.3. The Effect of Income Distribution Coefficient on the Level of Labor in Medical Institutions. According to formula (9), the first partial derivative of $\lambda_{1}$ with respect to $L_{2}$ can be obtained as follows:

$$
\frac{\partial \lambda_{1}}{\partial L_{2}}=-a_{2} A^{-(1 / \alpha)} \alpha^{-1} \beta^{-(\beta / \alpha)} \lambda_{1}^{-(\beta / \alpha)} \frac{\alpha \lambda_{1}}{\lambda_{1}-\beta} .
$$

Formula (14) reflects the influence of medical institutions' labor input level on the pension institutions' income distribution coefficient. According to formula (14), the second partial derivative of $\lambda_{1}$ with respect to $L_{2}$ can be obtained as follows:

$$
\frac{\partial^{2} \lambda_{1}}{\partial L_{2}^{2}}=-a_{2}^{2} A^{-(2 / \alpha)}\left(\frac{\beta}{\alpha}\right)^{3} \beta^{-(2 / \alpha)} \lambda_{1}^{-(2 / \alpha)}\left(\frac{\alpha \lambda_{1}}{\lambda_{1}-\beta}\right)^{3}\left(\frac{\lambda_{1}}{\alpha}+\frac{\alpha-\beta}{\alpha}\right) .
$$

Formula (15) reflects the influence of medical institutions' labor input level on the growth rate of pension institutions' income distribution coefficient.

Formulas (14) and (15) show that the incentive relationship between the distribution income coefficient of pension institutions and the labor level of medical institutions is directly related to the size relationship between $\alpha$ and $\beta$. Therefore, the value of pension institutions' distribution income coefficient is discussed below in the two cases of $\beta-$ $\alpha<0$ and $\beta-\alpha>0$ :

Case 1. When $\beta-\alpha<0,0<\beta<0.5,0.5<\alpha<1$. Thus, the input of labor has a greater influence on the total output than the input of fixed assets.

(1) When $0<\lambda_{1}<\beta<0.5,\left(\partial \lambda_{1} / \partial L_{2}\right)>0$ can be obtained from formula (14). Therefore, the income distribution coefficient of pension institutions will increase with increasing medical institutions' labor input level. According to formula (15), $\left(\partial^{2} \lambda_{1} / \partial L_{2}^{2}\right)>0$ can be obtained. Thus, the income distribution coefficient of pension institutions increases marginally with increasing medical institutions' labor input level.

(2) When $\beta<\lambda_{1}<1,\left(\partial \lambda_{1} / \partial L_{2}\right)<0$ can be obtained from formula (14), and $\left(\partial^{2} \lambda_{1} / \partial L_{2}^{2}\right)<0$ can be obtained from formula (15). Therefore, the pension institutions' income distribution coefficient and its growth rate decrease with increasing medical institutions' labor level.

Case 2. When $\beta-\alpha>0,0<\alpha<0.5,0.5<\beta<1$. Thus, the input of fixed assets has a greater influence on the total output than the input of labor.

(1) When $0<\lambda_{1}<\beta-\alpha,\left(\partial \lambda_{1} / \partial L_{2}\right)>0$ can be obtained from formula (14). Therefore, the income distribution coefficient of pension institutions will increase with increasing medical institutions' labor input level. According to formula (15), $\left(\partial^{2} \lambda_{1} / \partial L_{2}^{2}\right)<0$ can be obtained. Thus, the income distribution coefficient of pension institutions decreases marginally with increasing medical institutions' labor input level.
(2) When $\beta-\alpha<\lambda_{1}<\beta$, $\left(\partial \lambda_{1} / \partial L_{2}\right)>0$ can be obtained from formula (14) and $\left(\partial^{2} \lambda_{1} / \partial L_{2}^{2}\right)>0$ can be obtained from formula (15). Thus, the pension institutions' income distribution coefficient and its growth rate increase with increasing medical institutions' labor level.

(3) When $\beta<\lambda_{1}<1, \quad\left(\partial \lambda_{1} / \partial L_{2}\right)<0$ can be obtained from formula (14) and $\left(\partial^{2} \lambda_{1} / \partial L_{2}^{2}\right)<0$ can be obtained from formula (15). Thus, the pension institutions' income distribution coefficient and its growth rate decrease with increasing medical institutions' labor level.

Theorem 3. Even if the labor level input or fixed asset input has a greater impact on the total output, the impact will increase with increasing labor input in medical institutions when the income distribution coefficient of pension institutions is relatively low. However, when the income distribution coefficient of pension service institutions increases to a certain high value, it will decrease with the improvement of the medical institutions' labor level.

To obtain a high income distribution coefficient, pension service institutions can actively negotiate and cooperate with medical institutions and formulate detailed cooperation rules when the income distribution coefficient of pension institutions is low, thereby encouraging medical institutions to improve their labor level. When pension institutions' income distribution coefficient is high, medical institutions accounted for a relatively low income distribution coefficient. Pension institutions' income distribution coefficient is then negatively related to labor input levels of medical institutions. Therefore, medical institutions can increase the labor input level to reduce the pension institutions' income distribution coefficient and increase their own income distribution coefficient to obtain additional profits.

\section{Analogue Simulation}

Numerical simulation analysis is the most effective way to test real-time dynamic data without numerous empirical validations. Hence, we analyze the impact of factors, such as the effort coefficient, the output elasticity of labor input, and fixed asset input on cooperative production input through simulation. We then study the incentive mechanism of labor level input and fixed asset input on income distribution of institutions.

\subsection{The Effect of Labor Input Level on Income Distribution} Coefficient of Pension Institutions under the Integrating Health and Care Services. In studying the effect of labor input level on the income distribution coefficient of pension institutions, we found that the output elasticity of labor input and fixed asset input and the profitability of the integrating health and care services have certain influence on the labor input of pension institutions. Let $\alpha=0.3, \beta=0.7$, $\alpha=0.5, \beta=0.5$, and $\alpha=0.7, \beta=0.3$. On this basis, let $A=5, a_{1}=2, A=8, a_{1}=2$, and $A=10, a_{1}=2$. The simulation results are shown in Figure 1 . 


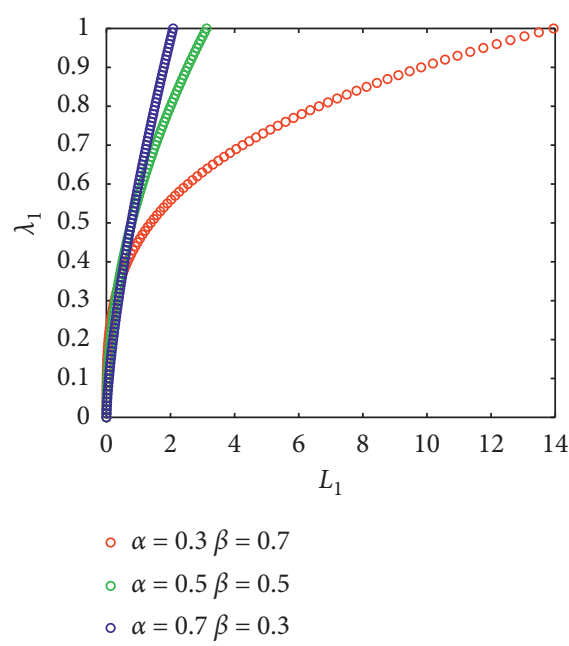

(a)

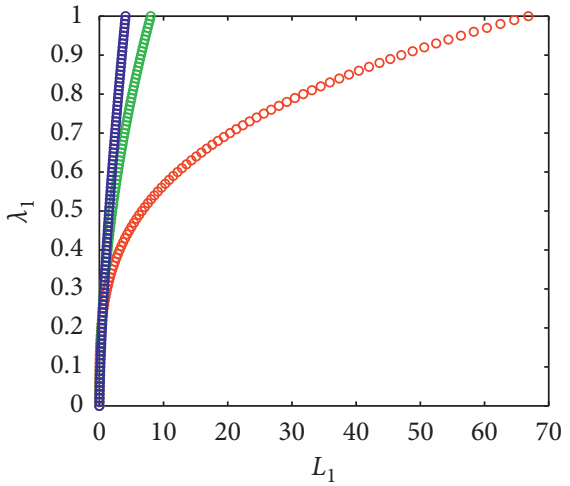

$$
\begin{aligned}
& \circ \alpha=0.3 \beta=0.7 \\
& \circ \alpha=0.5 \beta=0.5 \\
& \circ \alpha=0.7 \beta=0.3
\end{aligned}
$$

(b)

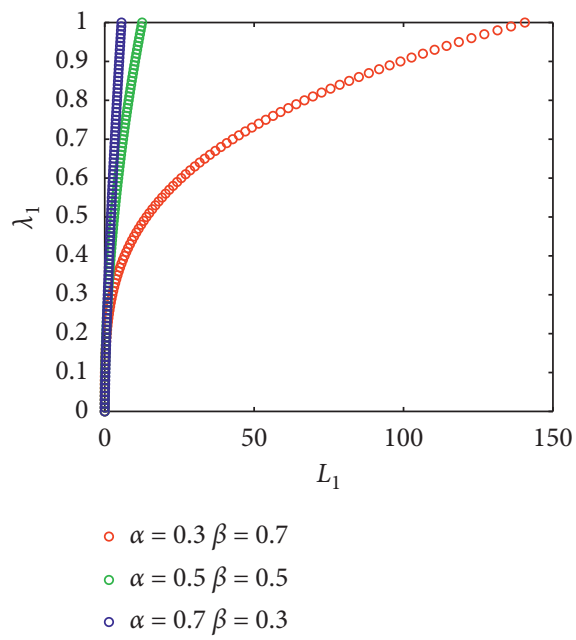

(c)

Figure 1: The influence mechanism of labor input level on the income distribution coefficient of pension institutions. (a) $A=5, a_{1}=2$. (b) $A=8, a_{1}=2$. (c) $A=10, a_{1}=2$.

As shown in Figure 1, pension institutions' income distribution coefficient will increase when the labor level of pension institutions is improved. Thus, the elderly groups who need integrating health and care services will pay increased attention to daily care, spiritual comfort, and so on. In addition, the income distribution coefficient of pension institutions will increase. By comparing Figures 1(a)-1(c), we found that the profitability of the integrating health and care services has little impact on the labor input level of pension institutions when the input of labor has greater influence on the total output than the input of fixed assets. However, when the input of fixed assets has a greater influence on the total output than the input of labor, the profitability of the integrating health and care services is better, and the more labor must be input for pension institutions to achieve a high income distribution coefficient.
3.2. The Effect of Fixed Assets Level on Income Distribution Coefficient of Pension Institutions under the Integrating Health and Care Services. In studying the effect of fixed assets level on the income distribution coefficient of pension institutions, we found that the effort coefficient of pension institutions and medical institutions, the output elasticity of labor input and fixed asset input, and the profitability of the integrating health and care services have certain influence on the fixed assets input of pension institutions. The numerical simulation is carried out under the different value relations of $a_{1}$ and $a_{2}$, which mainly include the following cases:

Case 1. When $0<a_{2}<(\alpha / 2) a_{1}$, analyze the effect of fixed assets investment on the income distribution coefficient of pension institutions.

When $\alpha>\beta$, the input of labor has a greater influence on the total output than the input of fixed assets. Let 
$\alpha=0.7, \beta=0.3, A=5$. The simulation result is shown in Figure 2(a). When $\alpha<\beta$, the input of fixed assets has a greater influence on the total output than the input of labor. Let $\alpha=0.3, \beta=0.7, A=5$. The simulation result is shown in Figure 2(b).

As shown in Figure 2, in early investment, the income distribution coefficient of pension institutions is positively correlated with their fixed assets investment. When the pension institutions' income distribution coefficient reaches a certain high value, it is negatively correlated with their fixed assets investment. When the fixed assets investment of pension institutions is certain and the effort coefficient of pension institutions and medical institutions is higher, the income distribution of pension institutions will increase. By comparing Figures 2(a) and 2(b), we found that the fixed assets input of pension institutions is relatively low when the input of fixed assets has a greater influence on the total output than the input of labor. The income distribution coefficient of pension institutions will then increase fast. As the fixed assets investment continues to increase, the income distribution coefficient will gradually slow down. In addition, under the condition that the profitability of the integrating health and care services remains unchanged and the input of fixed assets has a greater influence on the total output than the input of labor, pension institutions should invest additional fixed assets to obtain a high income distribution coefficient.

Case 2. When $(\alpha / 2) a_{1}<a_{2}<a_{1}$, analyze the effect of fixed assets investment on the income distribution coefficient of pension institutions.

(1) If $(\alpha / 2) a_{1}<a_{2}<\alpha a_{1}$, when $\alpha>\beta$, then the input of labor has greater influence on the total output than the input of fixed assets. Let $\alpha=0.7, \beta=0.3, A=5$. The simulation result is shown in Figure 3(a). When $\alpha<\beta$, the input of fixed assets has a greater influence on the total output than the input of labor. Let $\alpha=0.3, \beta=0.7, A=5$. The simulation result is shown in Figure 3(b).

(2) If $\alpha a_{1}<a_{2}<a_{1}$, when $\alpha>\beta$, the input of labor has a greater influence on the total output than the input of fixed assets. Let $\alpha=0.7, \beta=0.3, A=5$. The simulation result is shown in Figure 3(c). When $\alpha<\beta$, the input of fixed assets has a greater influence on the total output than the input of labor. Let $\alpha=0.3, \beta=0.7, A=5$. The simulation result is shown in Figure 3(d).

As shown in Figure 3, the income distribution coefficient of pension institutions is positively correlated with their fixed assets investment. If the fixed assets investment of pension institutions is certain and the effort coefficient of pension institutions and medical institutions is high, then the income distribution of pension institutions will increase. In comparing Figures $3(a)-3(d)$, we found that the input of fixed assets has a greater influence on the total output than the input of labor. In addition, the fixed assets input of pension institutions is relatively low, and the income distribution coefficient of pension institutions increases at a faster speed. As the fixed assets investment continues to increase, the income distribution coefficient gradually slows down. Under the condition that the profitability of the integrating health and care services remains unchanged and the input of fixed assets has a greater influence on the total output than the input of labor, pension institutions need to invest more fixed assets.

\subsection{The Effect of Labor Input Level of Medical Institutions} on Income Distribution Coefficient of Pension Institutions under the Integrating Health and Care Services. In studying the effect of labor input level of medical institutions on the income distribution coefficient of pension institutions, we found that the output elasticity of labor input and fixed asset input and the profitability of the integrating health and care services have certain influence on the fixed assets input of pension institutions. The numerical simulation is carried out under the two cases about $\beta<\alpha$ and $\beta>\alpha$. When $\beta<\alpha$, the input of labor has a greater influence on the total output than the input of fixed assets. Let $\alpha=0.7, \beta=0.3, a_{2}=1$. The simulation result is shown in Figure 4(a). When $\beta>\alpha$, the input of fixed assets has a greater influence on the total output than the input of labor. Let $\alpha=0.3, \beta=0.7, a_{2}=1$. The simulation result is shown in Figure 4(b).

As shown in Figure 4, the income distribution coefficient of pension institutions will increase with increasing labor input level in medical institutions. When the labor input level of medical institutions reaches the maximum, the income distribution coefficient of pension service institutions is negatively correlated with the labor level of medical institutions. By comparing Figures 4(a) and 4(b), we found that the maximum value of labor input in medical institutions increases if the profitability of the integrating health and care services is good. In addition, when the input of fixed assets has a greater influence on the total output than the input of labor, the maximum value of labor input in medical institutions is greater, and the income distribution coefficient of pension institutions is relatively higher when the labor level of medical institutions reaches the maximum value. However, when the input of labor has a greater influence on the total output than the input of fixed assets, the income distribution coefficient of pension institutions is relatively lower when the labor input level of medical institutions reaches its peak.

\section{Conclusion}

Considering the increasing aging problem, pension has become a hot topic of social concern. By using game theory and on the premise of the maximization about pension and medical institutions' own benefits, we constructed the utility model of resource allocation between pension and medical institutions under the integrating health and care services. We also explored the mutual incentive relationship between resource input and income distribution coefficient of pension and medical institutions. We then used computer numerical simulation technology to analyze and draw the following conclusions: 

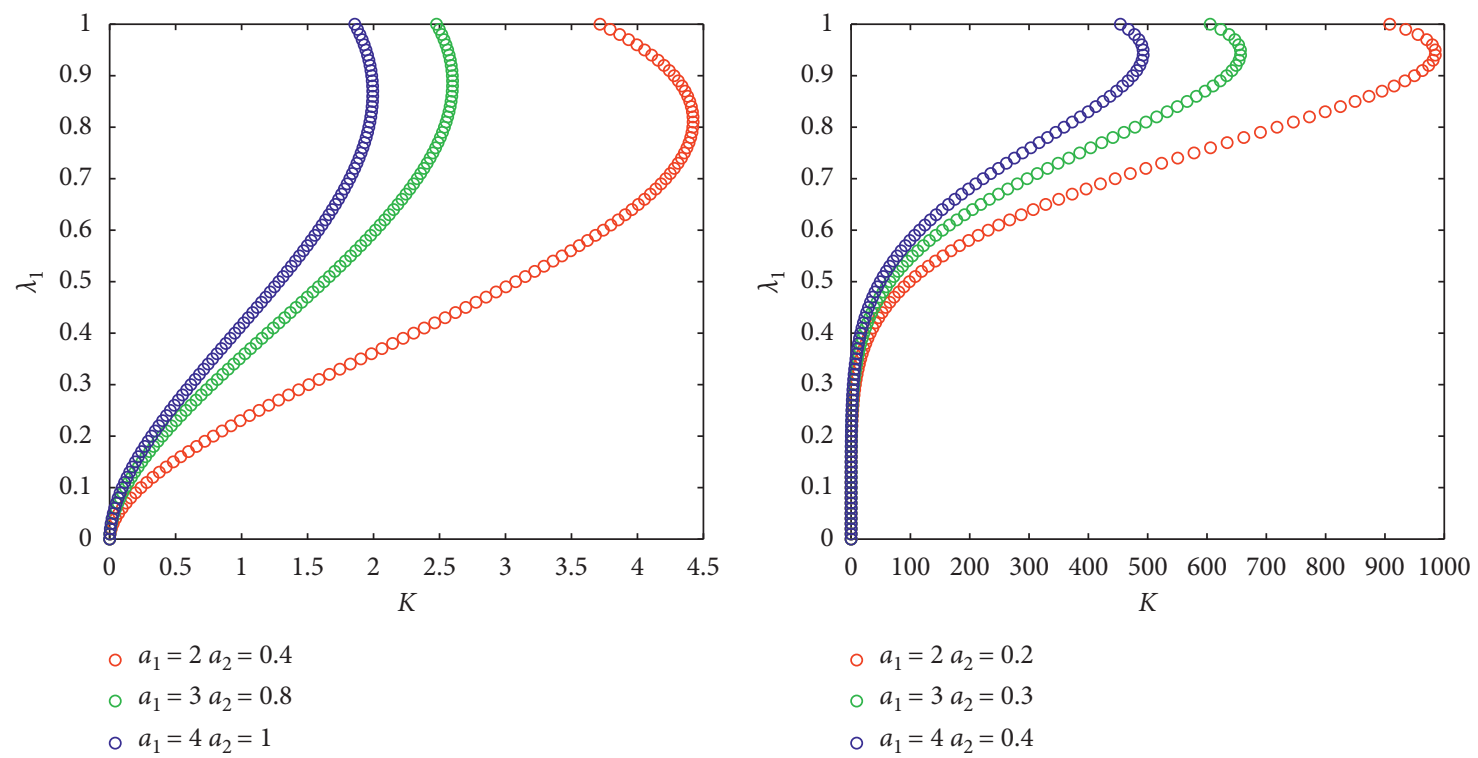

(a)

(b)

FIGURE 2: When $0<a_{2}<(\alpha / 2) a_{1}$, the influence mechanism of fixed asset investment on the income distribution coefficient of pension institutions. (a) $\alpha>\beta$. (b) $\alpha<\beta$.
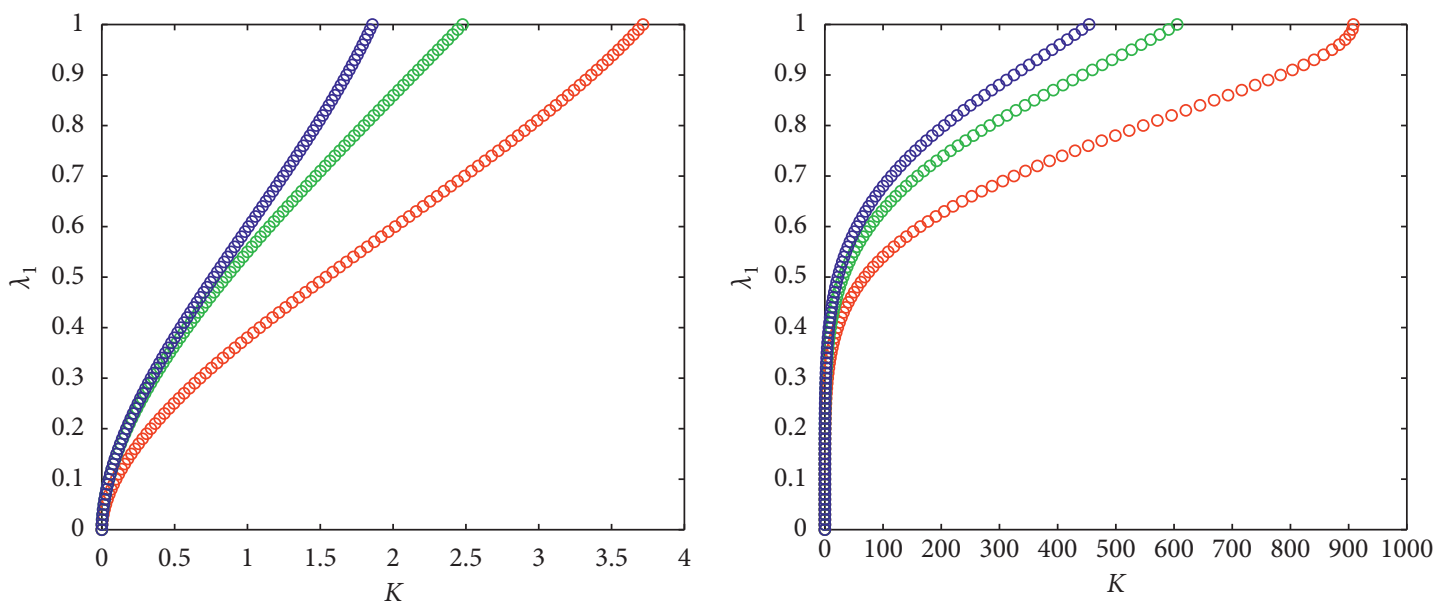
- $a_{1}=2 a_{2}=1$
○ $a_{1}=3 a_{2}=2$
○ $a_{1}=4 a_{2}=2$
○ $a_{1}=2 a_{2}=0.3$
○ $a_{1}=3 a_{2}=0.7$
○ $a_{1}=4 a_{2}=1$

(a)

(b)

Figure 3: Continued. 


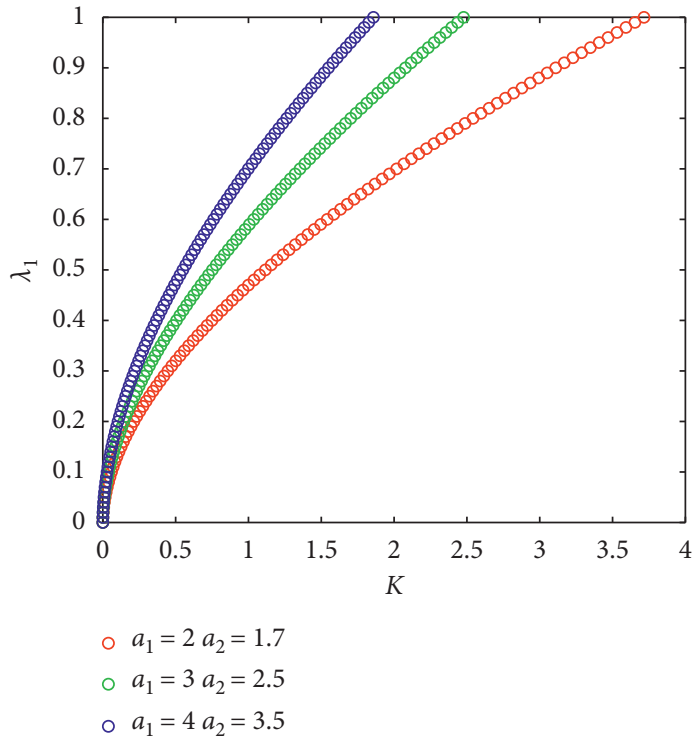

(c)

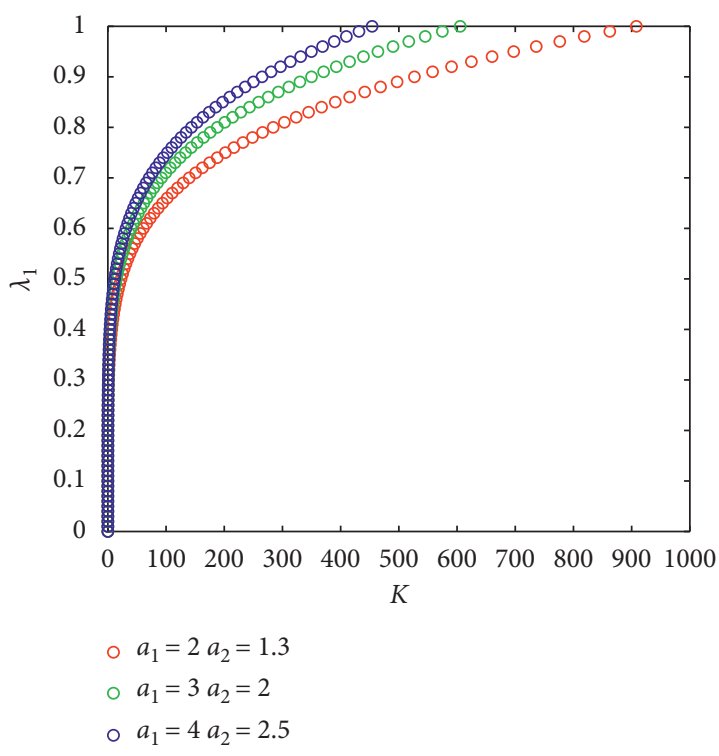

(d)

FIGURE 3: When $(\alpha / 2) a_{1}<a_{2}<a_{1}$, the influence mechanism of fixed asset investment on the income distribution coefficient of pension institutions. (a) $(\alpha / 2) a_{1}<a_{2}<\alpha a_{1}$ 且 $\alpha>\beta$. (b) $(\alpha / 2) a_{1}<a_{2}<\alpha a_{1}$ 且 $\alpha<\beta$. (c) $\alpha a_{1}<a_{2}<a_{1}$ 且 $\alpha>\beta$. (d) $\alpha a_{1}<a_{2}<a_{1}$ 且 $\alpha<\beta$.

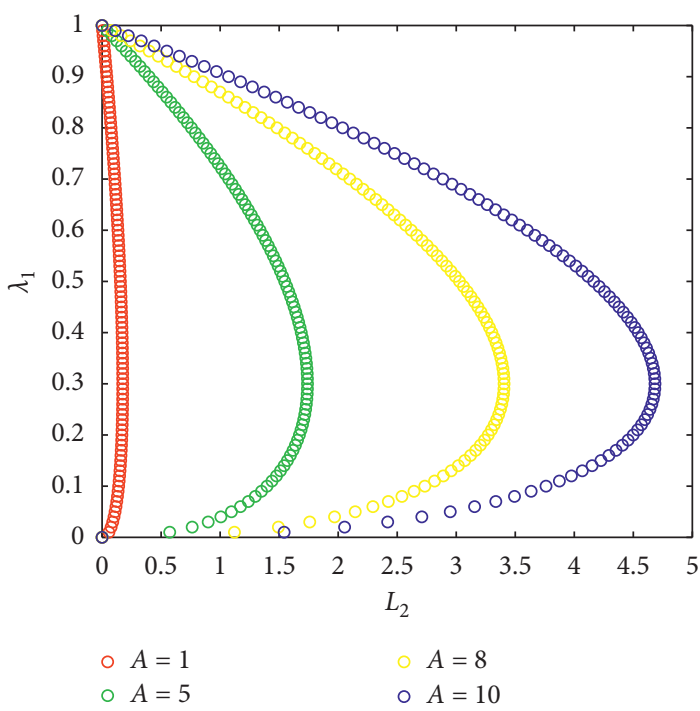

(a)

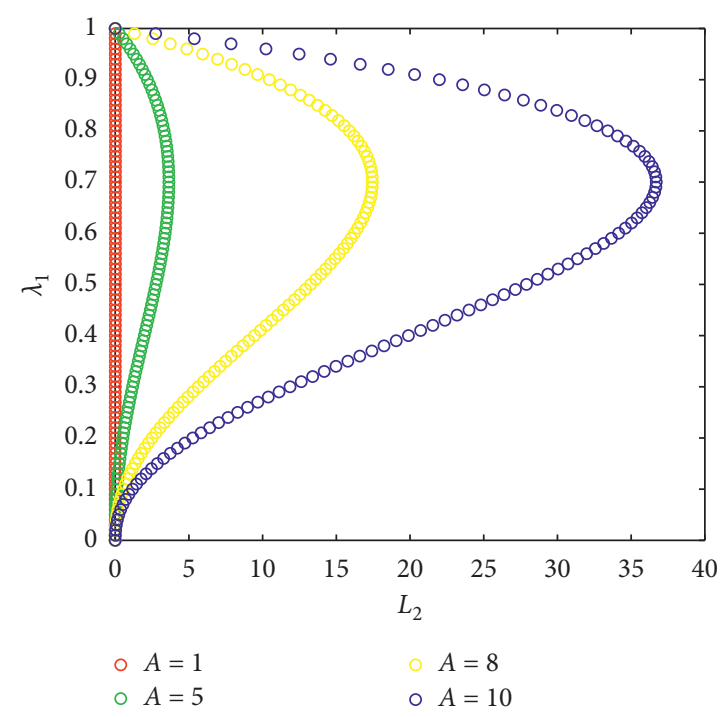

(b)

FIGURE 4: The influence mechanism of labor input level in medical institutions on the income distribution coefficient of pension institutions. (a) $\beta<\alpha$. (b) $\beta>\alpha$.

(1) As can be seen from the relationship between the labor input level of pension institutions and the income distribution coefficient of pension institutions, due to the mutual influence of pension institutions and medical institutions, the income distribution coefficient of medical institutions decreases with increasing income distribution coefficient of pension institutions. To prevent medical institutions from refusing medical cooperation due to the low income distribution coefficient, the labor input of pension institutions should be relaxed and not be increased blindly.

(2) The relationship between the fixed asset investment and the income distribution coefficient of pension institutions shows that pension institutions can increase the income distribution coefficient by expanding their investment in fixed assets. If the elderly who need the integrating medical and care services prefer more nursing beds, basic medical facilities, and other medical equipment, then pension 
institutions should invest in fixed assets. However, when elderly population shows an increased dependence on services, such as daily life care and spiritual comfort, the income distribution coefficient of pension institutions can be greatly affected by the fixed assets invested less.

(3) As can be seen from the relationship between the labor input level in medical institutions and the income distribution coefficient of pension institutions, when medical institutions account for a relatively low income distribution coefficient, they increase the labor input to reduce the income distribution coefficient of pension institutions and to improve their income distribution and obtain additional benefits. In addition, medical institutions are short on excellent doctors and nurses. If some medical staff were allocated to take care of the elderly, then their workload will increase significantly, and the service quality of medical institutions will decrease. Hence, pension institutions can actively negotiate, cooperate, and formulate detailed cooperation rules with medical institutions to encourage the latter to improve the labor level input when they offer integrating health and care services.

The main contribution of this paper is that we use game theory to construct the utility model of resource allocation between pension and medical institutions to explore how pension institutions and medical institutions invest resources into the integration of health and care services. However, there are still some limitations in our work. For example, the elderly service industry covers medical treatment, health, education, finance, tourism, etc., with a wide range of related branches and few relevant data, which is difficult to conduct in-depth research. Moreover, the relationship between the service demand of the elderly and the resource input of pension institutions and medical institutions has not been studied in depth. These questions can be topics of further research in the future. Through the study of time series, we further explore the relationship between each subject and each variable.

\section{Data Availability}

No data were used to support the findings of this study.

\section{Disclosure}

Tingqiang Chen, Jinnan Pan, Yuanping $\mathrm{He}$, and Jining Wang are the co-first authors.

\section{Conflicts of Interest}

The authors declare that they have no conflicts of interest.

\section{Authors' Contributions}

Tingqiang Chen, Jinnan Pan, Yuanping $\mathrm{He}$, and Jining Wang contributed equally to this work.

\section{Acknowledgments}

This work was supported by the National Natural Science Foundation of China (nos. 71871115, 71501094, and 71971111), the Major Project of Philosophy and Social Science Research in Colleges and Universities in Jiangsu Province (no. 2019SJZDA035), and the Innovation Team Project of Philosophy and Social Sciences in Colleges and Universities in Jiangsu Province (no. 2017ZSTD005).

\section{References}

[1] D. Szalewska, P. Niedoszytko, and K. Gierat-Haponiuk, "The impact of professional status on the effects of and adherence to the outpatient followed by home-based telemonitored cardiac rehabilitation in patients referred by a social insurance institution," International Journal of Occupational Medicine and Environmental Health, vol. 28, no. 4, pp. 761-770, 2015.

[2] E. R. McGrattan and E. C. Prescott, "On financing retirement with an aging population," Quantitative Economics, vol. 8, no. 1, pp. 75-115, 2017.

[3] A. C. Lyons, J. E. Grable, and S.-H. Joo, "A cross-country analysis of population aging and financial security," The Journal of the Economics of Ageing, vol. 12, pp. 96-117, 2018.

[4] T. Gorrindo, S. Chatterji, P. Kowal, Z. Epstein, and M. Weinstein, "A cross-country comparison of sociodemographic correlates of depression in the WHO study of global aging and adult health (SAGE)," Applied Demography and Public Health, vol. 3, pp. 45-60, 2013.

[5] E. Apodoulianaki, M. V. Tilborg, and H. S. M. Kort, "Visual functioning of aging care professionals and the influence of light, a brief literature study," Studies in Health Technology \& Informatics, vol. 217, no. 4, pp. 405-410, 2015.

[6] B. S. Jacobzone and J. Jenson, "Care allowances for the frail elderly and their impact on women care-givers," Oecd Labour Market \& Social Policy Occasional Papers, vol. 65, no. 65, pp. 532-539, 2000.

[7] N. Ikegami and J. C. Campbell, "Choices, policy logics and problems in the design of long-term care systems," Social Policy \& Administration, vol. 36, no. 7, pp. 719-734, 2003.

[8] J. M. Hartgerink, J. M. Cramm, A. J. D. Vos et al., "Situational awareness, relational coordination and integrated care delivery to hospitalized elderly in the Netherlands: a comparison between hospitals," BMC Geriatrics, vol. 14, no. 1, p. 3, 2014.

[9] I. N. Fabbricotti, B. Janse, W. M. Looman et al., "Integrated care for frail elderly compared to usual care: a study protocol of a quasi-experiment on the effects on the frail elderly, their caregivers, health professionals and health care costs," $B M C$ Geriatrics, vol. 13, no. 1, p. 31, 2013.

[10] J. Bao, X. J. Wang, Y. Yang, R.-Q. Dong, and Z.-F. Mao, “Can the medical-nursing combined care promote the accessibility of health services for the elderly in nursing home? A study protocol of analysis of the effectiveness regarding health service utilization, health status and satisfaction with care," West Indian Medical Journal, vol. 64, no. 5, pp. 514-520, 2015.

[11] D. B. Reuben, "Making hospitals better places for sick older persons," Journal of the American Geriatrics Society, vol. 48, no. 12, pp. 1728-1729, 2000.

[12] M. Wendy, B. Sally, W. Marianne, R. Olorenshaw, and N. Gracia, "Acute care management of older people with dementia: a qualitative perspective," Journal of Clinical Nursing, vol. 20, no. 3-4, pp. 420-428, 2011. 
[13] J. L. Powell, "Personalization and community care: a case study of the British system," Ageing International, vol. 37, no. 1, pp. 16-24, 2012.

[14] M. Zunzunegui, F. Béland, and A. Otero, "Support from children, living arrangements, self-rated health and depressive symptoms of older people in Spain," International Journal of Epidemiology, vol. 30, no. 5, pp. 1090-1099, 2001.

[15] M. E. Hughes and L. J. Waite, "Health in household context: living arrangements and health in late middle age," Journal of Health and Social Behavior, vol. 43, no. 1, pp. 1-21, 2002.

[16] R. Lund, P. Due, J. Modvig, B. E. Holstein, M. T. Damsgaard, and P. K. Andersen, "Cohabitation and marital status as predictors of mortality-an eight year follow-up study," Social Science \& Medicine, vol. 55, no. 4, pp. 673-679, 2002.

[17] C. Glendinning, "Breaking down barriers: integrating health and care services for older people in England," Health Policy, vol. 65, no. 2, pp. 139-151, 2003.

[18] T. Michel, "Integrating services for older people: a resource book for managers," International Journal of Integrated Care, vol. 5, no. 2, p. e19, 2005.

[19] K. Leichsenring and A. M. Alaszewski, Providing Integrated Health and Social Care for Older Persons: A European Overview of Issues at Stake, Ashgate Publishing Ltd., Aldershot, England, 2004.

[20] J. Reed, G. Cook, S. Childs, and B. McCormack, "A literature review to explore integrated care for older people," International Journal of Integrated Care, vol. 5, no. 1, p. e17, 2005.

[21] M. P. Fisher and C. Elnitsky, "Health and social services integration: a review of concepts and models," Social Work in Public Health, vol. 27, no. 5, pp. 441-468, 2012.

[22] H. A. Sultz, Health Care USA, Jones and Barlett Publishers, Burlington, MA, USA, 2006.

[23] S. S. Carson, P. B. Bach, L. Brzozowski, and A. Leff, "Outcomes after long-term acute care," American Journal of Respiratory and Critical Care Medicine, vol. 159, no. 5, pp. 1568-1573, 1999.

[24] P. Chatterji, N. Burstein, D. Kidder et al., Evaluation of the Program of All-Inclusive Care for the Elderly (PACE) Demonstration: The Impact of PACE on Participant Outcomes, Abt Associates, New York, NY, USA, 1998.

[25] R. Laura and B. A. Gadsby, PACE-Program of All Inclusive Care for the Elderly, Vol. 4, Age in Action, Cape Town, South Africa, 2007.

[26] M. Segelman, J. Szydlowski, B. Kinosian et al., "Hospitalizations in the program of all-inclusive care for the elderly," Journal of the American Geriatrics Society, vol. 62, no. 2, pp. 320-324, 2014.

[27] M. D. Fretwell, J. S. Old, K. Zwan, and K. Simhadri, "The elderhaus program of all-inclusive care for the elderly in North Carolina: improving functional outcomes and reducing cost of care: preliminary data," Journal of the American Geriatrics Society, vol. 63, no. 3, pp. 578-583, 2015.

[28] U. Polska, "The program of all-inclusive care for the elderly (PACE): the innovative and economically viable model of American geriatric care," Pielegniarstwo XXI Wieku/Nursing in the 21st Century, vol. 16, no. 1, pp. 51-61, 2017.

[29] M. Geraedts, G. V. Heller, and C. A. Harrington, "Germany's long-term-care insurance: putting a social insurance model into practice," The Milbank Quarterly, vol. 78, no. 3, pp. 375-401, 2000.

[30] B. Ahgren, "Patient choice and health care integration: a review of the consistency between two Swedish policy concepts," International Journal of Integrated Care, vol. 10, no. 6, p. e63, 2010.
[31] M. Maruthappu, A. Hasan, and T. Zeltner, "Enablers and barriers in implementing integrated care," Health Systems \& Reform, vol. 1, no. 4, pp. 250-256, 2015.

[32] S. Shimizutani, "The future of long-term care in Japan," AsiaPacific Review, vol. 21, no. 1, pp. 88-119, 2014.

[33] P. Ji, X. Ma, and G. Li, "Developing green purchasing relationships for the manufacturing industry: an evolutionary game theory perspective," International Journal of Production Economics, vol. 166, pp. 155-162, 2015.

[34] S. Li, Z. Yu, and M. Dong, "Construct the stable vendor managed inventory partnership through a profit-sharing approach," International Journal of Systems Science, vol. 46, no. 2, pp. 271-283, 2015.

[35] S. M. Alavi and C. Zhou, "Resource allocation scheme for orthogonal frequency division multiple access networks based on cooperative game theory," International Journal of Communication Systems, vol. 27, no. 8, pp. 1105-1125, 2015.

[36] D. Zhang, N. Wu, and X. Li, "The bilateral resource integration service system," in Proceedings of the Fourth International Conference on Computational \& Information Sciences, Chongqing, China, August 2012.

[37] Z. H. Wan and M. L. Zhang, "Value cocreation through resource integration: new insights into container inpection ecosystems the lens of service dominant logic and systems," in Proceedings of the IEEE International Conference on Service Operations \& Logistics, Dongguan, China, July 2013.

[38] J. Siltaloppi and S. L. Vargo, "Reconciling resource integration and value propositions-the dynamics of value co-creation," in Proceedings of the 47th Hawaii International Conference on System Sciences, Waikoloa, HI, USA, January 2014.

[39] S. P. Singaraju, Q. A. Nguyen, O. Niininen, and G. SullivanMort, "Social media and value co-creation in multi-stakeholder systems: a resource integration approach," Industrial Marketing Management, vol. 54, pp. 44-55, 2016.

[40] X. Guan, M. Li, and Y. Li, "Research on the resource integration of virtual industry cluster based on the complex network theory," in Proceedings of the International Conference on Industrial Economics System \& Industrial Security Engineering, Sydney, Australia, July 2016.

[41] K. Koskela-Huotari, B. Edvardsson, J. M. Jonas, D. Sörhammar, and L. Witell, "Innovation in service ecosystems-breaking, making, and maintaining institutionalized rules of resource integration," Journal of Business Research, vol. 69, no. 8, pp. 2964-2971, 2016.

[42] Q. Wang, K. Zhang, and D. Mu, "Research on the collaboration of express service network based on resource integration," in Proceedings of the 2016 International Conference on Logistics, Informatics and Service Sciences (LISS), Sydney, Australia, July 2016. 